\title{
Asset Management of Power Transformer Protective Devices in Transmission System
}

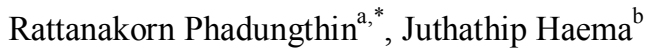 \\ ${ }^{a}$ Electronics Engineering Technology Department, College of Industrial Technology, King Mongkut's University of \\ Technology North Bangkok, Bangkok, 10800, Thailand \\ ${ }^{\mathrm{b}}$ Electrical Engineering Technology Department, College of Industrial Technology, King Mongkut's University of \\ Technology North Bangkok, Bangkok, 10800, Thailand \\ *rattanakorn.p@cit.kmutnb.ac.th
}

\begin{abstract}
Electrical utilities face high risks on acquisition and maintenance costs of their assets and try to achieve maximum utilization of their existing assets during the lifecycle. Asset management especially reliability centered maintenance is utilized for reducing maintenance risk. Power transformer is one of the most expensive components in electric power transmission. As protective devices are one of vital components of power transformer, asset management of power transformer protective devices in transmission system is proposed for preventing incipient faults in transmission system. Condition assessment and importance assessment are performed to set up maintenance tasks properly. The protective devices of loading transformers rating of $115 / 22 \mathrm{kV}$ and tie transformers rating of $230 / 115 \mathrm{kV}$ are selected to support the proposed model of maintenance risk reduction. Reliability and stability of the network are consequently improved.
\end{abstract}

Keywords: condition assessment, importance assessment, maintenance task.

\section{Introduction}

Asset management has played a key role in power system equipment of electrical utilities, especially power transformer that is one of the most critical components in high voltage substation and electric power transmission ${ }^{(1)}$. In addition, the transformer asset management is generally considered due to the substantial investments in the power transformers and the importance of the transformers as one of vital factors that result in the system reliability ${ }^{(2)}$. In electricity generation plants, power transformers transform the voltage of the generator to a higher level for the transmission of electricity in the main grid. Subsequently, the voltage must be transformed to a lower voltage so that the utilization of electrical energy can be done in various purposes. Power transformer contains a number of components: active part, bushing, arrester, on load tap changer, insulating oil, tank and protective equipment. Failures on any components can affect catastrophic consequences to the network.

As the protective devices are one of the defected components of the transformer, asset management of the protection should be performed. Condition assessment of the transformer protective devices is done by using visual inspection. Scoring and weighting techniques are applied to the assessment for classifying the condition into satisfied levels of maintenance strategies. Importance assessment of power transformer in the network is also performed for classifying the transformer importance into maintenance ranking.

This paper aims to present the proposed model of asset management of power transformer protective devices in the transmission system by applying the condition and the importance approaches with scoring and weighting techniques. The condition of the protection is assessed by using the visual inspection that is done every two weeks or a month, while the importance of the transformer is assessed by using operating characteristic of the transformer. Subsequently, both assessments are represented by color indicator: green, yellow and red. The data of the loading and tie transformers is used for the analysis. The asset management techniques for the protection can be then 
achieved with higher reliability and stability of the transformer in the transmission system.

\section{Asset Management Approach}

\subsection{Fundamental Asset Management}

Asset management ${ }^{(3-10)}$ is systematic and coordinated activities in which an organization optimally manages its assets, associated performance, risks and expenditures over their lifecycle for achieving its organizational strategic plan. Electrical utilities face a trouble on not only high acquisition cost of their assets especially power transformer, but also high maintenance cost during lifetime of power transformer. Thus, most of them need the asset management to maximize the utilization of their costly transformers. The successful asset management task can prolong the transformer lifetime with proper maintenance strategies and suitable schedule plan.

\subsection{Power Transformer Protection}

Normally, power transformer consists of various main components: active part, bushing, arrester, on load tap changer, insulating oil, tank and protective devices. The un-scheduled outages of the transformers due to unexpected failures are catastrophic in many cases to the network. The failures occurred from the protective devices are one of main causes affecting the transformer shutdown. The transformer protection involves eight devices as shown in Fig. 1.

(a) Transformer pressure relief

Transformer pressure relief (TPR) is installed on top of the tank cover or at a high position on the tank wall. It is utilized for relieving the pressure when high pressure from internal arc occurs, and can minimize the loss of insulating oil. The pressure relief device as shown in Fig. 1(a) operates if a large pressure builds inside tank caused by heavy arcing and heating affecting the oil to boil and bubble.

(b) Sudden pressure relay

Sudden pressure relay (SPR) is installed high up on the tank wall. It aims to alarm if there is a sudden pressure rise inside the tank. The relay as shown in Fig. 1(b) operates sensitively for only a little of pressure rising, caused by a small electrical fault inside the tank.

(c) On load tap changer pressure relief

On load tap changer pressure relief (OPR) is used for releasing the pressure when high pressure appears inside
OLTC compartment. The device is shown in Fig. 1(c).

(d) On load tap changer oil flow relay

On load tap changer oil flow relay (OFR) is used for protecting high pressure inside OLTC compartment due to arcing of connection inside the OLTC tank. It operates when the speed of oil flow exceeds the defined limit. The relay is shown in Fig. 1(d).

(e) Buchholz relay

Buchholz relay (BHR) is used for protecting incipient faults that generate a large amount of combustible gases in insulating oil. The relay operates when the quantity of accumulated gases over the defined limit. The relay is shown in Fig. 1(e).

(f) Rubber bag rupture

Rubber bag rupture (RBR) is used for checking the air bubble flowing into the insulating oil. When the rubber as shown in Fig. 1(f) is ruptured, oil leakage and oil level in sight glass require checking for damages.

(g) Oil temperature indicator

Oil temperature indicator (OTI) is used for measuring the top oil temperature of the power transformer. The indicator is shown in Fig. 1(g).

(h) Winding temperature indicator

Winding temperature indicator (WTI) is used for measuring the hot spot temperature of the transformer windings. The indicator is shown in Fig. 1(h).

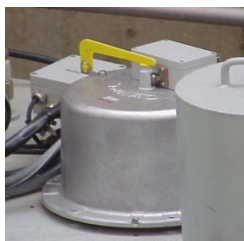

(a) TPR

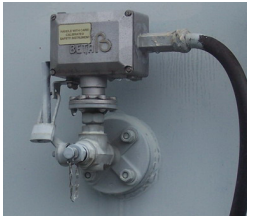

(d) OFR.

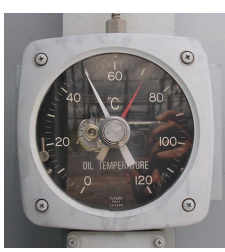

(g) OTI.

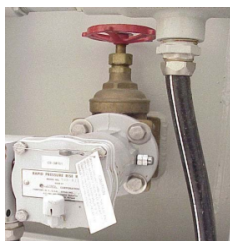

(b) SPR.

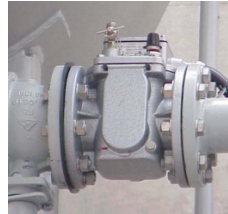

(e) BHR

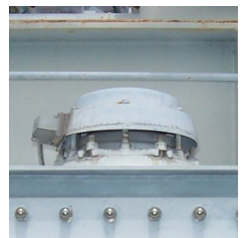

(c) OPR.

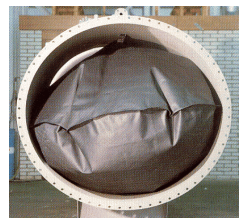

(f) RBR.

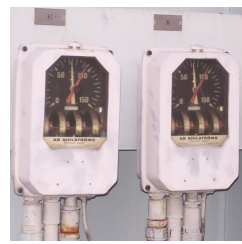

(h) WTI

Fig. 1. Protective devices of transformer. 


\subsection{Transformer Protection Asset Management}

The asset management of the protective devices can be classified into the following activities, as shown in Fig. 2.

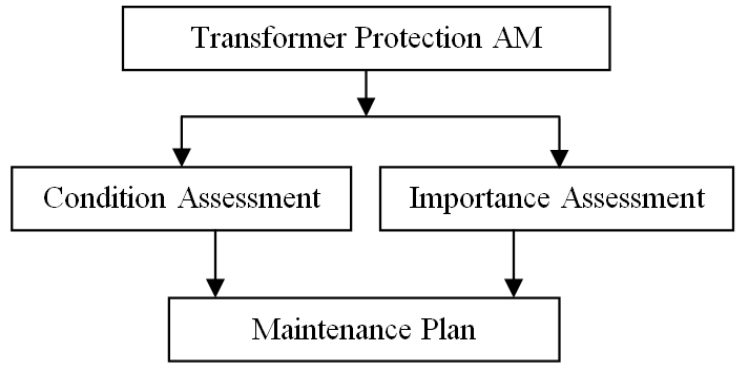

Fig. 2. Transformer protection asset management.

\subsection{Condition Assessment}

The condition assessment ${ }^{(11-13)}$ of the transformer protection is done by using the up-to-date data of visual inspection of individual protective devices. Electrical testing which is basically done and recorded for assessing the condition of other major components of the transformer is not necessary for the protective devices.

(a) Visual inspection

Visual inspection is physical inspection of transformer exterior. It reveals the condition information by using human senses of experienced staff. The inspection period is set by the electric utilities or manufacturers such as every two weeks or one month. The visual inspection of the transformer protection is gathered in Table 1. Oil leakage and operation of the protection are checked by the utility staff every two weeks for protecting the incipient faults.

Table 1. Visual inspection of protection

\begin{tabular}{|c|c|}
\hline Protective device & Visual inspection \\
\cline { 1 - 1 } Transformer pressure relief & \\
\cline { 1 - 1 } Sudden pressure relay & \\
\cline { 1 - 1 } OLTC pressure relief & \multirow{2}{*}{ Oil leakage } \\
\cline { 1 - 1 } OLTC oil flow relay & \\
\cline { 1 - 1 } Buchholz relay & \\
\cline { 1 - 1 } Rubber bag rupture & \\
\cline { 1 - 1 } Oil temperature indicator & \multirow{2}{*}{ Operation } \\
\cline { 1 - 1 } Winding temperature indicator & \\
\hline
\end{tabular}

\subsection{Importance Assessment}

The importance assessment ${ }^{(14-15)}$ of the transformer protection is performed by using the operating characteristics of the transformer, as written in Table 2.
Table 2. Importance criteria

\begin{tabular}{|c|}
\hline Importance items \\
\hline Load factor \\
\hline Load shedding \\
\hline N-1 criterion \\
\hline System stability \\
\hline Damage of property \\
\hline Social aspects \\
\hline Pollution \\
\hline
\end{tabular}

\subsection{Maintenance Action}

When asset management is concerned to maximize the asset utilization and to reduce the maintenance risk, maintenance plan will be clarified. The maintenance types are classified into corrective maintenance, preventive maintenance, and reliability centered maintenance, as shown in Fig. 3.

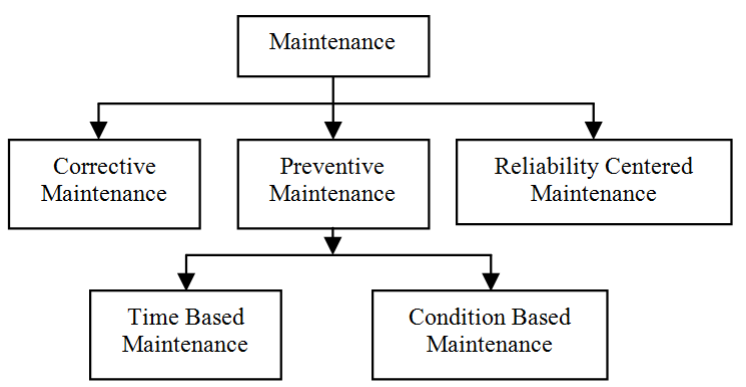

Fig. 3. Classification of maintenance action.

\subsection{Scoring and Weighting Technique}

Scoring $^{(16)}$ relies on transformer condition experts. Relative terms such as "normal" and "degradation" refer to operating condition, industry accepted levels, or baseline levels of considered devices. Weighting factor means weighting number of each considered criteria that imply a precision to the assessment.

The assessment methodology is performed by using the scoring and weighting technique, as written in (1).

$$
\% A I=\frac{\sum_{i=1}^{n}\left(S_{i} * W_{i}\right)}{\sum_{i=1}^{n}\left(S_{\max _{, i}} * W_{i}\right)} * 100
$$

Where $\% A I$ means assessment index; $S_{i}$ means individual score; $S_{\max , i}$ is maximum score; $W_{i}$ is weighting factor; and $n$ is the number of considered items. 


\subsection{Maintenance Selection}

Maintenance task selection for the transformer protective devices follows their obtained condition. The maintenance is divided into three levels, as shown in Fig. 4.

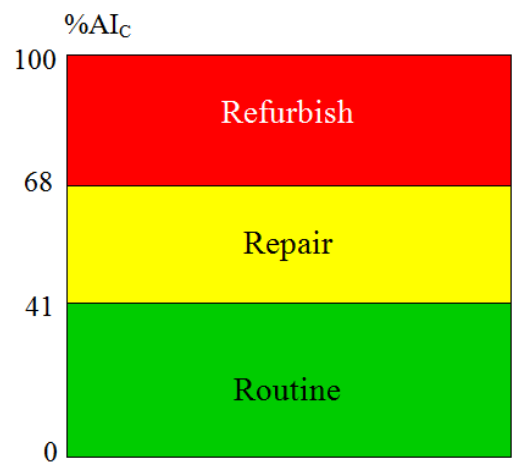

Fig. 4. Maintenance tasks of protective devices.

The percentage of the condition assessment index, $\% \mathrm{AI}_{\mathrm{C}}$, is defined by the calculation of the scores and the weighting numbers. Routine maintenance is selected for good condition when the $\% \mathrm{AI}_{\mathrm{C}}$ is $0-41 \%$; repairing is selected for $42 \%-68 \%$ with suspect condition; and refurbishing is selected for $69 \%-100 \%$ with poor condition. They are represented by green, yellow red indicators, respectively.

When a fleet of the power transformers in the system is considered in the assessment, even the acquisition cost of the protective devices is not expensive, transformer ranking of first maintenance may be necessary. Hence, the ranking will follow the importance assessment as represented by $\% \mathrm{AI}_{\mathrm{I}}$ in Fig. 5. Similar to the condition, the obtained $\% \mathrm{AI}_{\mathrm{I}}$ is calculated by the scores and weighting numbers of the operating characteristic items. Low transformer importance is for $0-42 \%$; medium importance is for $43 \%-68 \%$; and high importance is for $69 \%-100 \%$. They are represented by green, yellow and red indicators, respectively.

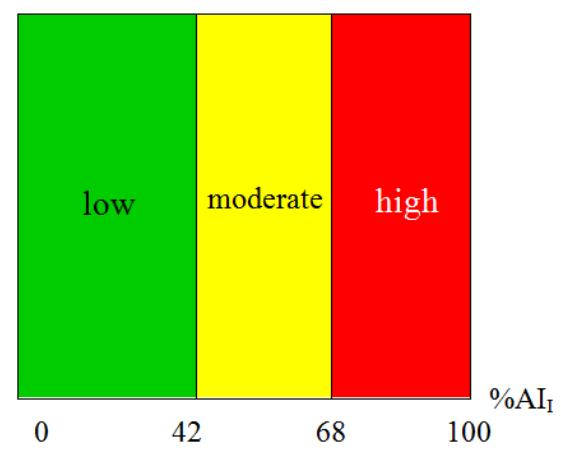

Fig. 5. Importance of protective devices.

\section{Results and Analysis}

As the transformers rating of $115 / 22 \mathrm{kV}$ and $230 / 115$ $\mathrm{kV}$ are mostly installed in the system, their available data is collected and used in the analysis. The $115 / 22 \mathrm{kV}$ loading transformers are T1, T2, T3, T4 and T5, while the 230/115 $\mathrm{kV}$ tie transformers are T6, T7, T8, T9 and T10.

(a) Condition Maintenance Task

The data of visual inspection of the loading transformer protection is written in Table 3, whereas that of the tie transformer protection is gathered in Table 4.

Table 3. Visual inspection of loading transformer

\begin{tabular}{|c|c|c|c|c|c|}
\hline Device & $\mathrm{T} 1$ & $\mathrm{~T} 2$ & $\mathrm{~T} 3$ & $\mathrm{~T} 4$ & T5 \\
\hline TPR & normal & normal & normal & $\begin{array}{c}\text { dry oil } \\
\text { stain }\end{array}$ & $\begin{array}{c}\text { dry oil } \\
\text { stain }\end{array}$ \\
\hline SPR & normal & normal & normal & normal & normal \\
\hline OPR & normal & normal & normal & normal & normal \\
\hline OFR & normal & normal & normal & normal & normal \\
\hline BHR & normal & normal & normal & normal & normal \\
\hline RBR & normal & normal & normal & normal & normal \\
\hline OTI & normal & $\begin{array}{c}\text { rusty } \\
\text { needle }\end{array}$ & $\begin{array}{l}\text { rusty } \\
\text { needle }\end{array}$ & $\begin{array}{l}\text { rusty } \\
\text { needle }\end{array}$ & $\begin{array}{l}\text { rusty } \\
\text { needle }\end{array}$ \\
\hline WTI & normal & $\begin{array}{c}\text { rusty } \\
\text { needle }\end{array}$ & normal & normal & $\begin{array}{l}\text { rusty } \\
\text { needle }\end{array}$ \\
\hline$\% \mathrm{AI}_{\mathrm{C}}$ & 33.33 & 42.42 & 37.88 & 42.42 & 46.97 \\
\hline Cond. & good & suspect & good & suspect & suspect \\
\hline
\end{tabular}

Table 4. Visual inspection of tie transformer

\begin{tabular}{|c|c|c|c|c|c|}
\hline Device & T6 & $\mathrm{T} 7$ & $\mathrm{~T} 8$ & T9 & $\mathrm{T} 10$ \\
\hline TPR & $\begin{array}{l}\text { dry oil } \\
\text { stain }\end{array}$ & $\begin{array}{l}\text { dry oil } \\
\text { stain }\end{array}$ & normal & normal & normal \\
\hline SPR & normal & normal & normal & $\begin{array}{l}\text { dry oil } \\
\text { stain }\end{array}$ & $\begin{array}{c}\text { dry oil } \\
\text { stain }\end{array}$ \\
\hline OPR & $\begin{array}{l}\text { dry oil } \\
\text { stain }\end{array}$ & $\begin{array}{l}\text { dry oil } \\
\text { stain }\end{array}$ & $\begin{array}{l}\text { dry oil } \\
\text { stain }\end{array}$ & normal & $\begin{array}{c}\text { dry oil } \\
\text { stain }\end{array}$ \\
\hline OFR & normal & normal & normal & normal & $\begin{array}{c}\text { dry oil } \\
\text { stain }\end{array}$ \\
\hline BHR & normal & normal & normal & $\begin{array}{l}\text { dry oil } \\
\text { stain }\end{array}$ & $\begin{array}{c}\text { dry oil } \\
\text { stain }\end{array}$ \\
\hline RBR & normal & normal & normal & normal & $\begin{array}{c}\text { wet oil } \\
\text { stain }\end{array}$ \\
\hline OTI & normal & $\begin{array}{c}\text { rusty } \\
\text { needle }\end{array}$ & $\begin{array}{l}\text { rusty } \\
\text { needle }\end{array}$ & $\begin{array}{c}\text { rusty } \\
\text { needle }\end{array}$ & normal \\
\hline WTI & $\begin{array}{c}\text { rusty } \\
\text { needle }\end{array}$ & $\begin{array}{c}\text { rusty } \\
\text { needle }\end{array}$ & normal & $\begin{array}{c}\text { rusty } \\
\text { needle }\end{array}$ & $\begin{array}{c}\text { rusty } \\
\text { needle }\end{array}$ \\
\hline$\% \mathrm{AI}_{\mathrm{C}}$ & 45.45 & 50.00 & 40.91 & 51.52 & 62.12 \\
\hline Cond. & suspect & suspect & good & suspect & suspect \\
\hline
\end{tabular}


(b) Importance Maintenance Task

The data of importance assessment is written in Table 5 for the five loading transformers and Table 6 for the five tie transformers. The calculated importance index, \% $\% \mathrm{AI}_{\mathrm{I}}$, shows that all loading transformers are in moderate importance. When the condition and the importance are considered together, the transformers T2, T4 and T5 that are in suspect condition are in moderate importance. The descending ranking of repairing the protective devices is T5, $\mathrm{T} 2$ and $\mathrm{T} 4$. For the tie transformers, the $\% \mathrm{AI}_{\mathrm{I}}$ shows that the transformers T6, T8 and T9 are in high importance. In addition, the protective devices of the transformer T9 are maintained firstly due to the highest importance (84.62\%) as the transformer has no $\mathrm{N}-1$ criterion and is installed in high pollution location with $31 \mathrm{~mm} / \mathrm{kV}$.

Table 5. Importance of loading transformer

\begin{tabular}{|c|c|c|c|c|c|}
\hline Device & T1 & $\mathrm{T} 2$ & T3 & $\mathrm{T} 4$ & T5 \\
\hline load & 0.7 & 0.7 & 0.6 & 0.5 & 0.5 \\
\hline Shed. & no shed & step 3 & step 1 & step 2 & step 1 \\
\hline N-1 & yes & yes & no & no & no \\
\hline $\begin{array}{c}\text { system } \\
\text { sta. }\end{array}$ & loading & loading & loading & loading & loading \\
\hline damage & $\begin{array}{l}\text { fire } \\
\text { wall }\end{array}$ & none & oil pitch & $\begin{array}{c}\text { oil } \\
\text { pitch }\end{array}$ & fire wall \\
\hline social & suburb & suburb & suburb & suburb & suburb \\
\hline $\begin{array}{l}\text { pollut. } \\
{[\mathrm{mm} / \mathrm{kV}]}\end{array}$ & 16 & 20 & 16 & 16 & 20 \\
\hline$\% \mathrm{AI}_{\mathrm{I}}$ & 53.85 & 56.41 & 58.97 & 53.85 & 56.41 \\
\hline Imp. & mod. & mod. & mod. & mod. & mod. \\
\hline
\end{tabular}

Table 6. Importance of tie transformer

\begin{tabular}{|c|c|c|c|c|c|}
\hline Device & T6 & T7 & T8 & T9 & T10 \\
\hline load & 0.6 & 0.7 & 0.6 & 0.6 & 0.5 \\
\hline shed. & step 1 & step 1 & no shed & no shed & step 3 \\
\hline N-1 & no & yes & yes & no & yes \\
\hline $\begin{array}{c}\text { system } \\
\text { sta. }\end{array}$ & loading & tie & tie & loading & loading \\
\hline damage & fire wall & $\begin{array}{c}\text { fire } \\
\text { wall }\end{array}$ & $\begin{array}{c}\text { oil } \\
\text { pitch }\end{array}$ & oil pitch & fire wall \\
\hline social & industry & suburb & suburb & industry & industry \\
\hline $\begin{array}{c}\text { pollut. } \\
\text { [mm/kV] }\end{array}$ & 20 & 20 & 20 & 31 & 16 \\
\hline \hline $\begin{array}{c}\% \mathrm{AI} \\
\text { I }\end{array}$ & 71.79 & 58.97 & 69.23 & 84.62 & 53.85 \\
\hline Imp. & high & mod. & high & high & mod. \\
\hline
\end{tabular}

\section{Conclusions}

Protective devices of power transformer in electric transmission system also need asset management techniques for reducing maintenance risk, maximizing their utilization and preventing incipient fault occurrences. The transformer protection asset management consists of two indices: condition assessment and importance assessment. Both assessments are used with scoring and weighting techniques to set up maintenance plan. Visual inspection is performed for evaluating the protection condition, while operating characteristic is utilized for evaluating the transformer importance. The indices are represented by three color indicators: green for good condition and for low importance, yellow for suspect condition and moderate importance, as well as red for poor condition and high importance. The transformer protection with poor condition and higher importance is maintained firstly. The maintenance actions of the condition evaluation are routine, repair and refurbish.

Due to available data, the loading and tie transformers are selected for the assessment. The transformer protections of $\mathrm{T} 5$ for the loading type and $\mathrm{T} 9$ for the tie type are maintained firstly as they are in suspect condition with higher importance than the others. The condition and the importance of the T5 are $46.97 \%$ and $56.41 \%$, respectively. Those of the T9 are $51.52 \%$ and $84.62 \%$, respectively. Consequently, using this proposed model of the asset management for the transformer protection in the transmission system can reduce the maintenance risk and improve the system reliability as the incipient faults are prevented.

\section{Acknowledgment}

The authors gratefully acknowledge King Mongkut's University of Technology North Bangkok (KMUTNB) and the Power Transformer Maintenance Department at Electricity Generating Authority of Thailand (EGAT) for supporting and providing the data for this work.

\section{References}

(1) H.P. Berg, N. Fritze : "Reliability of main transformers”, RT\&A, 2, pp. 52-69, March, 2011

(2) A.E.B. Abu-Elanien, M.M.A. Salama : "Asset management techniques for transformers", JEPSR, pp. 456-464, 2010 
(3) M.R. Hodkiewicz, R. Pascual : "Education in engineering asset management-current trends and challenges", International Physical Asset Management Conference, Tehran, 2006

(4) S.S. Bhandari, N. Chakpitak, K. Meksamoot, T. Chandarasupsang : "Knowledge engineering approach for power transformer asset management", JEST, 7, NO. 1, pp. 73-88, 2012

(5) British standards insulation, PAS 55: "Asset Management Part I: Specification for the Optimized Management of Physical Infrastructure Asset”, 2004

(6) Cigre working group C1.1 : "Asset Management of Transmission Systems and Associated Cigre Activities", December, 2006

(7) R.E. Brown, B.G. Humphrey :, "Asset management for transmission and distribution", IEEE Power and Energy Magazine, 2005

(8) J. Schneider, A. Gaul, C. Neumann, J. Hograefer, W. Wellssow, M. Schwan, A. Schnettler : "Asset management techniques", Power Systems Computation Conference, Belgium, August, 2005

(9) X. Zhang, E. Gockenbach : "Asset management of transformers based on condition monitoring and standard diagnosis", IEEE Electrical Insulation Magazine, Vol. 24, NO. 4, pp. 26-40, 2008

(10) G. Balzer, K. Bakie, H.J. Haubrich, C. Neumann, C. Schorn : "Selection of an optimal maintenance and replacement strategy of $\mathrm{HV}$ equipment by a risk assessment process", Cigre Session B3-103, 2006

(11) M. Wang, A.J. Vandermaar, K.D. Srivastava: "Review of condition assessment of power transformer in service”, Electrical Insulation Magazine, IEEE, 2002

(12) W.H. Tang, K. Spurgeon, Q.H. Wu, Z.J. Richardson : "An evaluated reasoning approach to transformer condition assessments", IEEE Transactions on Power Delivery, Vol. 19, No. 4, October, 2004

(13) United States department of the interior bureau of reclamation: "Transformer Maintenances", Facilities Instructions, Standards and Techniques, 3-30, October, 2000

(14) G. Balzer, O. Schmitt, A. Schneider, S. Gal, F. Balasiu, K. Bakic, M. Vidmar: "Life cycle assessment of substations: A procedure for an optimized asset management", Cigre Session 23-302, 2002

(15) G. Balzer, T. Orlowska, M. Halfmann, C. Meumann, A. Strnad: "Life cycle management of circuit-breakers by application of reliability centered maintenance", Cigre Session 13-103, 2000
(16) A. Naderian, S. Cress, R. Piercy, F. Wang, J. Service: "An approach to determine the health index of power transformers”, IEEE, ISEI, pp. 192-196, 2008 